\section{ICD corporate communication and its determinants: evidence from Italian listed companies' websites}

ICD corporate communication and its determinants

\author{
Giuseppe Nicolò
}

1209

Department of Management and Innovation Systems, University degli Studi di Salerno, Fisciano, Italy

Natalia Aversano

Department of Mathematics, Computer Science and Economics, University of Basilicata, Potenza, Italy

Giuseppe Sannino

Department of Economics, University of Campania Luigi Vanvitelli, Capua, Italy, and

Paolo Tartaglia Polcini

Department of Management and Innovation Systems, University degli Studi di Salerno, Fisciano, Italy

\begin{abstract}
Purpose - This study aims to analyse the extent and type of online intellectual capital (IC) disclosure provided by a sample of 117 Italian listed companies. The study also seeks to identify possible determinants of the extent and type of intellectual capital disclosure (ICD) practiced by Italian listed companies via the Web.

Design/methodology/approach - A content analysis is conducted to investigate the extent and type of online ICD provided through websites by a sample of 117 Italian listed companies. Two multivariate ordinary least squares regression models are applied to estimate the associations proposed in the research hypotheses.

Findings - The results show that Italian listed companies are exploiting the potential of websites to satisfy the information needs of investors and other stakeholders in relation to strategic IC-based corporate resources, with a particular focus on external capital. For the most part, ICD is conveyed in narrative form. Moreover, while the size and board independence positively affect both the extent and type of ICD, profitability exerts a positive influence only on the extent of online ICD.

Originality/value - Unlike previous ICD studies, which focussed on annual reports, this study explores an emerging and innovative tool to convey ICD, namely, the website. In today's world, websites are considered to be the most expedient and effective tools for sharing and transmitting information, including IC; they are a vehicle that can shift the IC focus from the organisation to the wider ecosystem.
\end{abstract}

Keywords Intellectual capital, Disclosure, Websites, Italian listed companies

Paper type Research paper

(C) Giuseppe Nicolò, Natalia Aversano, Giuseppe Sannino and Paolo Tartaglia Polcini. Published by Emerald Publishing Limited. This article is published under the Creative Commons Attribution (CC BY 4.0) licence. Anyone may reproduce, distribute, translate and create derivative works of this article (for both commercial and non-commercial purposes), subject to full attribution to the original publication and authors. The full terms of this licence may be seen at http://creativecommons.org/ licences/by/4.0/legalcode
Received 30 March 2020
Revised 22 June 2020
2 October 2020

Accepted 30 October 2020 
MEDAR

29,5

\section{Introduction}

Disclosing intellectual capital (IC) entails "the revelation of information that was previously secret or unknown" (Dumay, 2016, p. 178). The growing awareness of the relevance of intellectual capital disclosure (ICD) both in terms of improving investors' resource allocation and enhancing stakeholders' decision-making processes, coupled with the general absence of mandatory IC reporting up to now, has encouraged a plethora of scholars to devote considerable efforts to investigating voluntary ICD practices in both the private and public sectors in recent decades (Cuozzo et al., 2017). However, the majority of ICD research up to now has focussed on annual reports as a possible data source, showing discouraging results in terms of the actual level of ICD provided by organisations (Cuozzo et al., 2017; Dumay and Guthrie, 2017). This has led to progressive stagnation of ICD research which has yielded increasingly less significant results over the years (Dumay, 2016; Dumay and Guthrie, 2017).

In more recent times, however, emerging innovations in corporate reporting, such as integrated reporting (IR) and online channels such as websites, Facebook and Twitter, have breathed new life into ICD research (Dumay and Guthrie, 2017; Lardo et al., 2017; Lombardi and Dumay, 2017). Accordingly, also motivated by the emergence of the fourth stage of IC research, scholars are being called upon to go beyond annual reports and to investigate the emerging and innovative tools organisations may exploit to provide ICD and create knowledge for the ecosystem in which they operate (Lombardi and Dumay, 2017; La Torre et al., 2018; Ndou et al., 2018). In particular, online channels such as websites, whose structure has improved considerably in recent years as a result of digital technological innovations, have been welcomed as a "relevant contributor to IC disclosure [...] able to generate massive, variable and valuable amounts of data” (Ndou et al., 2018, p. 500).

Websites are the optimal tool for the transmission of large, complex masses of digital data and, in addition, are capable of exploiting Web 2.0 technologies such as hypertexts and hyper-links, HTML pages, audio, video and data analytics. This, in turn, enhances the accessibility, interactivity, timeliness and usability of information for investors and other stakeholders (Secundo et al., 2017; La Torre et al., 2018; Ndou et al., 2018). On this basis, online channels should be front and centre for researchers seeking to investigate voluntary ICD practices (Lombardi and Dumay, 2017; Massaro et al., 2018; Manes Rossi et al., 2018).

In the context of the above arguments, the present research aims to enhance the understanding of the extent and type of online ICD provided by a sample of 117 Italian nonfinancial companies listed on the Italian Stock Exchange in 2019. The ultimate goal of the study is to examine some possible explanatory factors relating to corporate size, profitability, leverage, high-tech industry involvement and corporate governance attributes (board size and board independence) that may drive the extent and type of ICD provided by Italian listed companies via the Web.

To this end, a manual content analysis was conducted on the websites of a sample of 117 listed Italian companies. Two ordinary least squares (OLS) multivariate regression models were then estimated to analyse the determinants affecting the extent of online ICD.

This paper provides a novel contribution to the literature, as it answers the call to go beyond traditional annual reports and investigate an alternative tool used to convey ICD voluntarily (Cuozzo et al., 2017; Dumay and Guthrie, 2017). Thus, while most studies analysing voluntary levels of ICD up to now were focussed on annual report as the main data source, which ultimately signalled the progressive stagnation of ICD research, this study explores websites as an optimal vehicle for the transmission of IC information. Moreover, broadening the scope of applications of previous similar research (Striukova et al., 2008; Sharma and Kaur, 2016; Duff, 2018), this study also provides insights about the factors that could explain practices of IC voluntary disclosure made by listed firms through 
websites, paying special attention to corporate governance attributes in terms of board size and board independence. In doing so, the study examines whether factors typically associated with voluntary ICD provided through traditional annual reports are also associated with both the extent and type of ICD conveyed through websites.

The paper is presented in seven sections. Section 2 contains a review of the literature, including a discussion about the potential of internet landscape in providing information on IC and an analysis of previous ICD studies, culminating in a description of the research objectives. Section 3 outlines the development of the hypotheses, while Section 4 explains the research methodology applied. Sections 5 and 6 present and discusses the content analysis and the results of the regression models. Finally, Section 7 presents the concluding remarks focus on the implications and limitations of the research.

\section{Literature review}

\subsection{New patterns for intellectual capital communication in the digital era}

IC has been defined as "the sum of everything everybody in a company knows that gives it a competitive edge" (Edvinsson and Malone, 1997, p. 44). Specifically, IC is composed of a dynamic set of interconnected types of capital, namely, human, internal (structural) and external (relational). When properly managed and valued, these capitals make a pivotal contribution to the value creation process, enabling companies to obtain a sustainable competitive advantage and, consequently, to achieve superior economic and financial performance (Duff, 2018; Goebel, 2019).

The growing awareness of the relevance of IC has stimulated a greater demand from investors and other stakeholders for reliable and comprehensive information on IC resources and their contribution to the value creation process; it has also emphasised the need for managers to correctly identify and manage IC (Bruggen et al., 2009; Haji and Ghazali, 2013; Melloni, 2015).

More specifically, information on IC is essential:

- for managers, to improve the process of defining objectives and developing strategies, as well as to encourage the implementation of business models focussed on the exploitation of intangible resources in the value creation process; and

- for investors and other stakeholders, to reduce information asymmetry and improve their resource allocation and decision-making processes, as a higher level of IC information enables a more accurate assessment of the company's current and potential economic value and the risks and opportunities arising from its activities (Bukh et al., 2005; Bruggen et al., 2009; Terblanche and De Villiers, 2019).

However, traditional financial reports largely neglect the relevance of a wide range of intangible assets and provide only a limited perspective on the actual value of IC elements (Sonnier, 2008; Bruggen et al., 2009). The international accounting standards issued by the International Accounting Standards Board provide a narrow definition of intangible resources, as well as restrictive recognition criteria, which limits, in reality, the accounting of intangibles to a restricted batch of resources that are either covered by specific legal rights (e.g. patents and trademarks) or are externally acquired (IAS 38). Most IC-related resources, such as employee knowledge, companies' reputation or basic research, remain excluded, while those meeting the relevant recognition criteria are initially measured at a value (in other words, historical cost) that only partially reflects their real economic value (e.g. patents and trademarks) (Forte et al., 2019; Nicolò, 2020).

As a consequence, traditional financial reports have gradually lost their information usefulness, causing an increase in the gap between the market value and the book value of many companies (Sonnier, 2008; Bruggen et al., 2009). This gap can be traced back to a hidden or unaccounted 
MEDAR 29,5

capital that is an array of intangible resources that are excluded from financial statements but are recognised by the market as strategic sources of value creation and competitive advantage; in other words, the IC (Bukh et al., 2005; Bruggen et al., 2009; Forte et al., 2019).

To address the accounting limitations referred to above, academics and practitioners have, in recent decades, started to develop alternative models and frameworks to identify and report IC accurately. Moreover, some companies (e.g. Skandia, Brembo and Infosys) have made initial attempts to generate specific IC reports. However, no framework has ever achieved the necessary consensus to be considered as a universal reference for ICD (Forte et al., 2019). Even pioneering companies such as Skandia interrupted reporting activities after a few years due to the absence of external coercive pressures attuned with the unwillingness of managers to provide commercially sensitive information on value creation sources (Dumay, 2016).

Nevertheless, in recent years, the rise of the fourth industrial revolution has entailed progressive digitalisation of internal value creation processes and accounting and reporting practices, paving the way for the communication process between companies and stakeholders to evolve (Dumay and Guthrie, 2017). In particular, the emergence of modern digital technologies and format such as social, mobile, cloud (SoMoClo), internet of things (IoT), multimedia portals, eXtensible Business Reporting Language (XBRL) and Big Data (BD) in the form of huge volumes of digital data that can be shared and transmitted through different sources, is contributing in revolutionising corporate reporting activities (A1Htaybat and von Alberti-Alhtaybat, 2017; Dumay and Guthrie, 2017; Secundo et al., 2017). Thereby, an innovative scenario for sharing knowledge and reporting financial and nonfinancial information to the whole of investors and other stakeholders is progressively emerging (Al-Htaybat and von Alberti-Alhtaybat, 2017; La Torre et al., 2018).

In this context, the Web is widely deemed to be the best channel through which companies can collect, manage and share information through hypertexts and hyperlinks, HTML pages, audio, video and portals (Al-Htaybat and von Alberti-Alhtaybat, 2017; Ndou et al., 2018). The use of the Web is likely to increase the accessibility, interactivity, timeliness and usability of information and therefore overcome the static nature of information sharing and the delays associated with the transmission of information through traditional financial reports (AlHtaybat and von Alberti-Alhtaybat, 2017; Manes Rossi et al., 2018; Ndou et al., 2018). In particular, while as the mid-1990s, firms have being started to realise the first corporate websites mainly conveying financial information and publish electronically their traditional print-based annual reports, in past years, with the introduction of new digital presentation languages (e.g. XBRL); tools (e.g. hyperlinks and hypertexts); and, technological innovations (e.g. $\mathrm{BD}$ and $\mathrm{SoMoClo}$ ), internet disclosure practices have become the mainstream to provide investors and other stakeholders with directly usable and higher quality information (Boubaker et al., 2011; Gajewski and Li, 2015; Al-Htaybat and von Alberti-Alhtaybat, 2017). As such, following the growing digitisation, firms have been started to provide an increasing extent of information that goes beyond the financial domain and that are largely neglected by traditional communication tools (e.g. annual reports), such as those pertaining to IC resources, to facilitate investors and other stakeholders' information gathering, analysing and evaluation processes (Gajewski and Li, 2015; Al-Htaybat and von Alberti-Alhtaybat, 2017). The use of websites today represents the backbone of corporate communication, as it allows to reduce the information asymmetries that usually occurs between internal managers and uninformed investors and other stakeholders, providing positive effects in terms of increased capital market efficiency and stakeholders' confidence (Striukova et al., 2008; Boubaker et al., 2011; Gajewski and Li, 2015).

The emergence of modern digital technologies has breathed new life into ICD research, as it paves the way for enhanced corporate transparency and the provision of a satisfactory level of 
disclosure on IC resources and their contribution to the value creation process in companies (Massaro et al., 2017; La Torre et al., 2018; Ndou et al., 2018). Accordingly, scholars are being called upon to go beyond annual reports and to investigate the emerging and innovative tools organisations may use to provide ICD and create knowledge for the ecosystem in which they operate (Lombardi and Dumay, 2017; La Torre et al., 2018; Ndou et al., 2018).

\subsection{Prior research on intellectual capital disclosure and research objectives}

Overall, IC research has evolved through four main stages (Dumay and Garanina, 2013; Secundo et al., 2017; Ndou et al., 2018). During the first stage of research, academics and practitioners focus mainly on studies aimed at acquiring awareness and recognising the potential of IC. During this phase, the need to report and measure IC led to the creation of multiple frameworks and guidelines. In the second stage, a process of consolidation and diffusion of IC research occurred and additional methods to identify, measure and report IC was developed (Dumay and Garanina, 2013). During this phase, many scholars, based on the main frameworks created to report IC, started to analyse the level of voluntary ICD made by companies. In the third stage, researchers focussed on undertaking a concrete analysis of the practical implications of using ICrelated resources in business management processes (Dumay and Garanina, 2013). The fourth and final stage expanded IC research boundaries by considering the relationships between the company, the stakeholders and the wider ecosystem in which the company operates. According to Dumay (2016, p. 180), the underlying rationale of this stage is to:

[...] abandon reporting, and concentrate on how an organisation discloses what was previously secret or unknown, so that all stakeholders understand how an organisation takes into consideration its ethical, social and environmental impacts.

Previous ICD research was mainly included within the second and third stages, focussing on annual reports as a possible source of information. This research was conducted worldwide and was largely based on investigating samples of companies operating in different geographical contexts (Bozzolan et al., 2003; Guthrie et al., 2006; Oliveira et al., 2006; Li et al., 2008; Bruggen et al., 2009; Goebel, 2019). Most of these studies reported an overall low level of ICD and a predisposition to external capital disclosure (Guthrie and Petty, 2000; Bozzolan et al., 2003; Guthrie et al., 2006; Bruggen et al., 2009; Goebel, 2019). Also, the main form of disclosure was narrative and discursive rather than quantitative (Guthrie and Petty, 2000; Guthrie et al., 2006; Nurunnabi et al., 2011; Haji and Ghazali, 2013).

A part of these studies also investigates the possible determinants of ICD, mainly identified in size (Bozzolan et al., 2003; Guthrie et al., 2006; Oliveira et al., 2006; Li et al., 2008; Bruggen et al., 2009; Hidalgo et al., 2011; Nurunnabi et al., 2011; Ferreira et al., 2012; Haji and Ghazali, 2013); profitability (Cerbioni and Parbonetti, 2007; Li et al., 2008; Haji and Ghazali, 2013); leverage (Haji and Ghazali, 2013); high-tech industry involvement (Bozzolan et al., 2003; Oliveira et al., 2006; Bruggen et al., 2009; Goebel, 2019). In addition, the studies looked at corporate governance, mainly investigating the following attributes: board size (Cerbioni and Parbonetti, 2007; Hidalgo et al., 2011; Haji and Ghazali, 2013) and board independence (Cerbioni and Parbonetti, 2007; Li et al., 2008; Haji and Ghazali, 2013).

At the same time, other authors investigated the determinants of the level of ICD provided through initial public offering (IPO) prospectuses (Bukh, 2005; Abdul Rashid et al., 2012), evidencing that the extent of managerial ownership before the IPO, as well as industry type, influenced the amount of voluntary ICD provided (Bukh et al., 2005). Further significant drivers of ICD included board size, board independence and leverage. Moreover, Garcia-Meca and Martinez (2005) observed that 
MEDAR 29,5

size positively influences the level of ICD provided by Spanish listed companies in presentations to financial analysts.

In more recent years, the awareness of the limitations of the annual reports accused to be not originally designed to provide information on the IC, excessively backwards-looking and largely focussed on financial issues, attuned with the emergence of innovations in corporate reporting such as the IR; sustainability reports (SR) and online channels, has encouraged scholars to abandon annual reports to investigate alternative and more suitable tools firms may exploit to disclose IC information (Cuozzo et al., 2017; Lardo et al., 2017; Massaro et al. (2017).

Accordingly, Cinquini (2012) focussed on a sample of SR prepared by Italian listed companies, observing that ICD is mainly expressed in non-financial, quantitative and nontime specific terms, with a low level of forward-looking information. Other scholars (Melloni, 2015; Haji and Anifowose, 2017; Terblanche and De Villiers, 2019) embraced IR as the "new hope for IC reporting" (Dumay, 2016, p. 175). They observed that IR is likely to increase the level of ICD (Terblanche and de Villiers, 2019) and that IC and human capital disclosure categories tend to increase over time (Haji and Anifowose, 2017). However, limited disclosure of quantitative and forward-looking information still persists, as well as a tendency of IR adopters to exploit ICD to deflect attention from their declining profitability (Melloni, 2015). In line with the fourth stage of IC research, several researchers in both the private and public sectors, in a bid to examine voluntary ICD practices, started to explore online media tools, such as websites (Manes Rossi et al., 2018); IMBs after internet stock message boards (Massaro et al., 2017; social networks (Lardo et al., 2017); blog posts (Massaro et al., 2018; both websites and different online media channels (Ndou et al., 2018); and both traditional (annual reports) and emerging communication tools such as corporate social responsibility reports and websites (Sharma and Kaur, 2016; Duff, 2018). In this context, Sharma and Kaur (2016) examined the extent of intangible assets disclosure both in annual reports and on websites of top 11 Indian listed companies, finding an overall low level of disclosure with a prevalence for the internal capital category. On the contrary, Duff (2018) observed that the UK professional accounting firms make extensive use of Web pages to convey information about their external (relational) capital, while Lardo et al. (2017) highlighted that popularity metrics in social media are determinants of the value of human and relational capital in professional football clubs, also providing examples to evidence how social media can be valid tools for disclosing IC information in a relevant and timely manner. Similarly, the study carried out by Massaro et al. (2017) on IMBs confirms that Web 2.0 applications are a valid method for disclosure of IC information. Further, the study by Massaro et al. (2018) demonstrated how managers and practitioners focus on both IC and sustainability issues when publishing posts on CSRwire.com.

Finally, in the university context, both Manes Rossi et al. (2018) and Ndou et al. (2018) provided empirical evidence in support of websites as suitable tools for disclosing IC information to stakeholders.

Therefore, drawing on previous research and following a suggestion by scholars (Dumay, 2016; Cuozzo et al., 2017; Lombardi and Dumay, 2017; Lardo et al., 2017; Ndou et al., 2018) to look beyond traditional reporting tools, the present paper intends to contribute to the existing literature by exploring an alternative tool for IC information disclosure, in view of the emerging changes in technology and communications.

Thus, in keeping with the fourth stage of IC research, this study proposes an analysis of the websites of a sample of 117 Italian listed companies to empirically investigate both the extent and type of ICD. In addition, unlike previous studies exploring websites (Striukova et al., 2008; Sharma and Kaur, 2016; Duff, 2018), this study also intends to enhance the understanding of the possible determinants of online ICD provided by Italian listed firms, 
extending the study of the most commonly examined variables in previous ICD studies conducted on annual reports, to the website domain.

\section{Theoretical background and hypothesis development}

Drawing on previous ICD studies and following the stakeholder theory perspective, six hypotheses are developed and discussed below, of which two represent structural variables (size and leverage), two represent corporate governance attributes (board size and board independence) and the remaining two are linked to performance (profitability) and market dimension (high-tech industry involvement).

According to the stakeholder theory, regardless the industry sector or the output produced, each organisation faces with a multitude of subjects involved or interested in its activities and having different perspectives and expectations - the stakeholders (Gray et al., 1995; Deegan, 2000). Being strategic providers of financial and non-financial resources, stakeholders are able to influence the effectiveness and efficiency of companies' activities and can therefore have a significant impact on corporate performance and long-term survival (Gray et al., 1995; Guthrie et al., 2006). For this reason, the organisation must do its utmost to obtain constant support and approval from stakeholders, correctly addressing and balancing their expectations and informational needs (Gray et al., 1995; Deegan, 2000; Guthrie et al., 2006; Nicolò, 2020). It follows that an adequate amount of disclosure over and above the compulsory requirements, ranging from financial to non-financial issues and including information on corporate strategic resources (IC), is pivotal so that a company can meet stakeholders' information needs and demonstrate to them that it is acting in accordance with their expectations (Guthrie et al., 2006; Bruggen et al., 2009; Massaro et al., 2017; Nicolò, 2020). Due to their unique features, online tools such as websites can be used to reach a wider forum of stakeholders in a timely and more accessible manner, providing them with a higher level of ICD than traditional reports (Massaro et al., 2017; Manes Rossi et al., 2018).

\subsection{Size}

Overall, the larger the company, the more stakeholders there are who need information about its activities and the relevant IC-based strategic resources (Garcia-Meca and Martinez, 2005; Guthrie et al., 2006). Larger companies, in particular, are highly visible and exposed to social and political scrutiny (Garcra-Meca and Martinez, 2005; Haji and Ghazali, 2013; Melloni, 2015); this creates more incentive for such companies to disclose a greater level of IC information to mitigate external pressures, reduce political costs and create confidence amongst stakeholders (Oliveira et al., 2006; Ferreira et al., 2012).

Moreover, larger companies tend to have more economic and financial resources to invest in the adoption of new technological and innovative tools (such as the websites), which can improve both internal and external information systems and overcome the shortcomings of traditional accounting systems (Oliveira et al., 2006; Boubaker et al., 2011; Lee and Blouin, 2019).

Empirically, the majority of scholars detected a positive relationship between the size of companies and the level of ICD provided through different communication tools (Bozzolan et al., 2003; Guthrie et al., 2006; Oliveira et al., 2006; Haji and Ghazali, 2013; Terblanche and de Villiers, 2019).

Therefore, a positive relationship is expected between Italian listed companies' size and the level of ICD provided through their websites:

H1. There is a positive association between companies' size and their level of online ICD.
ICD corporate communication and its determinants

1215 
MEDAR

29,5

1216

\subsection{Profitability}

Based on the stakeholder theory, in the case of higher profitability, ICD assumes a pivotal role, allowing companies to justify their profits and to demonstrate to shareholders and other stakeholders how that profitability is the result of long-term investments in the creation and development of IC resources (Oliveira et al., 2006; Ferreira et al., 2012). A higher level of ICD, especially when provided through more accessible and dynamic tools such as websites, also allows more profitable companies to distinguish themselves from less profitable ones, generating, in turn, favourable market effects in terms of positive returns, a decrease in the cost of capital, and a reduction in the undervaluing of shares (Garcia-Meca and Martinez, 2005; Oliveira et al., 2006; Boubaker et al., 2011). Scholars also contend that more profitable companies have more economic resources to adopt new technologies and develop IT capabilities and competencies which may improve the communication flow with investors and other stakeholders (Lee and Blouin, 2019).

From an empirical perspective, several scholars (Garcia-Meca and Martinez, 2005; Cerbioni and Parbonetti, 2007; Li et al., 2008; Haji and Ghazali, 2013) found a positive association between companies' profitability and their level of ICD, although others failed to detect any significant relationship between the two (Oliveira et al., 2006; Ferreira et al., 2012).

Therefore, based on the above discussions, the following hypothesis is proposed:

H2. There is a positive relationship between companies' profitability and their level of online ICD.

\subsection{Leverage}

In general, creditors and lenders concerned about the repayment of loans and interests, exert massive pressure on companies to disclose information about how financial resources are being used and about the present net value of investment projects undertaken using borrowed resources (Garcia-Meca and Martinez, 2005; Boubaker et al., 2011). Due to their relevance as a critical factor for success, particular attention is paid to investments in intangible assets, which may not be adequately disclosed on annual reports (Ferreira et al., 2012; Goebel, 2019). For all of these reasons, the voluntary ICD provided via alternative reporting tools such as IR or websites may acquire a pivotal role in satisfying creditors' informational needs about IC investments and in offering them reassurance (Bruggen et al., 2009; Goebel, 2019; Terblanche and De Villiers, 2019). Moreover, according to Abdul Rashid et al. (2012), in the case of highly leveraged companies, a greater level of ICD may contribute to a decrease in the cost of capital.

From an empirical standpoint, Abdul Rashid et al. (2012) and Haji and Ghazali (2013) found a positive and significant relationship between companies' leverage and their level of ICD, while other scholars did not observe any significant association (Garcia-Meca and Martinez, 2005; Oliveira et al., 2006; Terblanche and de Villiers, 2019). Conversely, in the German context, Goebel (2019) detected a negative and significant association between companies' leverage and their level of voluntary ICD, arguing that in German companies, lenders are usually also shareholders and thus experience fewer information asymmetry problems, meaning that they typically do not require additional IC information.

Based on the contrasting evidence above, this study posits the following hypothesis:

H3. There is a relationship between companies' leverage and the extent of their online ICD. 
Companies operating in knowledge-intensive (high-tech) industries invest heavily in intangible resources such as research and development (R\&D) and are characterised by a high rate of technology renewal, as well as by a high degree of tacit knowledge (Palazzi et al., 2020). Accordingly, such companies are expected to provide more voluntary ICD than other companies, through more accessible and timely tools such as websites to overcome the limitations of traditional financial reports and both reduce investors' uncertainty and risk perception and improve stakeholders' decision-making processes (Bozzolan et al., 2003; Oliveira et al., 2006). High-tech companies are also characterised by greater "technological readiness" (Lee and Blouin, 2019, p. 367), as they typically have a higher level of Information Technology (IT) sophistication, capabilities and technical expertise than other companies (Lee and Blouin, 2019) and rely upon digital technologies to support both internal management and external communication processes. This tends to bolster higher levels of Web disclosure (Boubaker et al., 2011; Lee and Blouin, 2019).

Most previous ICD studies (Bozzolan et al., 2003; Bukh et al., 2005; Oliveira et al., 2006; Bruggen et al., 2009; Goebel, 2019) provided empirical evidence supporting a positive relationship between high-tech industry involvement and ICD level. Moreover, Boubaker et al. (2011) observed that French IT companies tend to make a higher level of Web disclosure than other companies.

Therefore, based on the above discussion, the following hypothesis is proposed:

H4. There is a positive relationship between high-tech industry involvement and the level of online ICD.

\subsection{Corporate governance attributes: board size and board independence}

According to the stakeholder theory, an effective board should balance and harmonise the interests of the various stakeholders involved in organisational activities, promoting transparency and accountability through adequate levels of disclosure on financial and nonfinancial information such as IC (Li et al., 2008; Prado-Lorenzo and Garcia-Sanchez, 2010; Ntim et al., 2017).

The efficiency and effectiveness of a board of directors in fulfilling its monitoring duties and responsibilities strictly depends on its characteristics in terms of dimension and composition (Cerbioni and Parbonetti, 2007; Li et al., 2008). In particular, board size and board independence are two governance features that have a critical effect on the level of ICD.

Larger governing boards are expected to have greater monitoring capacity and ability to promote value creation activities due to the presence of a heightened stock of skills, technological expertise, competences and experience, as well as of a stronger connection with the external environment (Haji and Ghazali, 2013; Ntim et al., 2017). Therefore, from this standpoint, larger boards are deemed more able than smaller ones in terms of representing and managing the interests of different stakeholder groups by promoting the dissemination of a higher level of ICD (Haji and Ghazali, 2013).

However, from an opposing perspective, scholars posit that beyond a certain numerical threshold, coordination and communication problems may arise, resulting in slower decision-making processes (Cerbioni and Parbonetti, 2007; Abdul Rashid et al., 2012). This may outweigh the benefits arising from better monitoring capabilities and provoke negative effects on the level of disclosure that organisations provide (Cerbioni and Parbonetti, 2007; Hidalgo et al., 2011). From an empirical perspective, Cerbioni and Parbonetti (2007) found that board size positively influences human and external capital disclosure and negatively influences overall ICD. Further, Hidalgo et al. (2011), Abdul Rashid et al. (2012) and Haji and 
MEDAR 29,5

Ghazali (2013) provided empirical support for a positive relationship between board size and ICD level.

Another significant factor relating to boards is board independence, which may exert a relevant impact on the level of ICD companies provide. Independent board members are external referees; they are not involved in internal management activities and they have significant expertise and professional reputations to defend (Li et al., 2008; Hidalgo et al., 2011). Therefore, they are in a better position to exert greater control over managerial and board decisions, ensuring equity in decision-making processes and stimulating, in turn, higher levels of ICD (Cerbioni and Parbonetti, 2007; Li et al., 2008). Their role assumes a pivotal relevance in the context of the Italian companies whose boards are often composed of large dominant shareholders. These shareholders play a decisive role in the appointment of directors, as well as in the board and the committee agenda, exploiting their power to the detriment of minority shareholders' and external stakeholders' interests (Allegrini and Greco, 2013). In this case, independent directors should act to monitor the opportunistic behaviour of insiders (e.g. large controlling shareholders or relevant executive managers) and safeguard the interests of outsiders (e.g. less informed minority shareholders, outside shareholders or external stakeholders), promoting a higher level of disclosure, including IC (Allegrini and Greco, 2013; Haji and Ghazali, 2013). From a stakeholder theory perspective, independent members are also deemed particularly sensitive to social demands and more able than internal directors to protect the interests of stakeholders (Prado-Lorenzo and Garcia-Sanchez, 2010), ensuring higher levels of ICD (Li et al., 2008).

From an empirical perspective, Cerbioni and Parbonetti (2007), Li et al. (2008) and Haji and Ghazali (2013) observed a positive and significant relationship between board independence and ICD level, while both Hidalgo et al. (2011) and Terblanche and De Villiers (2019) failed to provide a significant association between board independence and ICD.

Accordingly, based on the above discussion, the following hypotheses are posited:

H5. There is a positive relationship between board size and the level of online ICD.

H6. There is a positive relationship between board independence and the level of online ICD.

\section{Research methodology}

\subsection{Sample selection and data sources}

This research focusses on all Italian non-financial companies listed on the Italian Stock Exchange in 2019. The Italian context is considered particularly interesting for the analysis of ICD because, since 1999, several government initiatives have been launched to elicit organisations in investing in IC resources (Bozzolan et al., 2003). In particular, listed companies have been chosen because they rely on capital markets to gain financial resources and face with a multitude of investors that requires information about IC to estimate firms' value and their future wealth creation capabilities (Bruggen et al., 2009). Moreover, they invest heavily in intangible resources and are characterised by a high rate of technology renewal of their production processes and information systems (Bozzolan et al., 2003; Palazzi et al., 2020).

The sample construction consists of three specific phases.

The first phase involved consulting the most recent Borsa Italiana database (referring to the year 2019), which is the main provider of real-time corporate governance, financial and market performance information on all Italian listed companies. As a result of this phase, an initial group of 200 Italian listed companies, belonging to 10 industry sectors, was retrieved. 
The second phase involved the identification and subsequent elimination of all financial, banking and insurance companies because of their specific disclosure requirements and accounting regulations. Thus, after this phase, 49 firms of that type were eliminated.

The third phase consisted of the collection of governance and financial data necessary to test the hypotheses and erase, from the final sample, companies for which such data were not available. Corporate governance information (board size and board independence) were gathered directly from firms' websites, while financial information (leverage, profitability and size) were retrieved from the AIDA Bureau van Dijk database. All data were gathered by referring to the past financial year available before the Web analysis, which was 2018. As such, after this final phase, another 34 companies were excluded from the sample due to the nonavailability of data. This led to a final sample of 117 Italian non-financial listed companies.

To investigate the extent and type of ICD provided by Italian listed companies, the analysis focussed on websites.

According to Lombardi and Dumay (2017, p. 2):

[.. . ] the annual report has long outlived itself as the best source of corporate disclosure because it contains backward looking information and is only a one-way means of presenting information rather than engaging with information users.

Therefore, websites have been chosen as the focus of the research because they present several advantages to corporate reporting practices as they facilitate greater accessibility, interactivity, timeliness and usability of information, overcoming the limitations of traditionally static and backwards-looking financial reports (Kelton and Yang, 2008; Al-Htaybat and von Alberti-Alhtaybat, 2017; Ndou et al., 2018).

In particular, compared to traditional reporting means, websites allow firms to reach a broader forum of stakeholders in a timely, dynamic and cost-effective manner (Kelton and Yang, 2008; Gajewski and Li, 2015; Dumay, 2016). Being based on a multitude of technological feature items (e.g. hyperlinks, multimedia tools, user-friendly applications, help site, site plan, internal search engine), websites facilitate the users' information gathering process, making real-time disclosures on both financial and non-financial issues largely accessible to all investors and other stakeholders (Kelton and Yang, 2008; Gajewski and Li, 2015; Dumay, 2016). As contended by Cormier et al. (2009, p. 4), the Web can be considered as the "best platform for stewardship and disclosure management, for financial, as well as non-financial information", as it ensures more flexibility than traditional tools both in the presentation and content of disclosure (Cormier et al., 2009).

Accordingly, internet disclosure offers firms rooms to improve the communication quality and reduce information asymmetry problems with uninformed investors and other stakeholders who increasingly rely on the internet to collect information that usually are not provided by traditional annual reports, such as those pertaining to IC resources (Cormier et al., 2009; Gajewski and Li, 2015; Dumay and Guthrie, 2017).

\subsection{Content analysis and intellectual capital disclosure}

Content analysis was used to investigate the extent and type of ICD provided through websites by the sample of 117 Italian listed companies.

Content analysis has been defined as a research technique for "making replicable and valid inferences from texts (or other meaningful matter) to the context of their use" Krippendorff (2004, p. 18). It is the most appropriate research method for investigating the extent and type of ICD, as it can be used to examine any publicly available information in a systematic, objective and reliable manner (Guthrie et al., 2004; Cuozzo et al., 2017).
ICD corporate communication and its determinants

1219 
MEDAR 29,5
A correct content analysis process involves four different stages:

(1) defining the coding framework;

(2) selecting the recording unit;

(3) the coding process; and

(4) assessing the level of reliability achieved (Bozzolan et al., 2003; Guthrie et al., 2004; Krippendorff, 2004).

To ensure the reliability and comparability of the study, the coding instrument was based on a well-established framework (Guthrie et al., 2004; Beattie and Thomson, 2007). Accordingly, the model adopted by Guthrie and Petty (2000), based on Sveiby's (1997) IC framework, was used as a coding framework. However, in line with previous studies (Guthrie et al., 2006; Striukova et al., 2008; Haji and Ghazali, 2013; Duff, 2018) to improve the suitability and accuracy of the checklist, slight amendments to the instrument needed to be made after a pilot test that was performed by two coders on a sample of 10 websites of companies involved in different industrial sectors.

Specifically, to avoid redundancy and confusion, the items "management philosophy" and "networking systems" were removed from the internal/structural capital category. In the external/relational capital category, according to Striukova et al. (2008) and Duff (2018), the item "company name" was changed in "company reputation" to include all information relating to external stakeholders' (e.g. client, suppliers, public institutions) perceptions of the company; while the items "Licensing agreements" and "Favourable contracts" were merged into one item, "Favourable contracts/licensing", which incorporates information about any type of contracts or licenses gained or acquired by the company, including franchising. Finally, the item "R\&D" was added to the external capital category as it is a core component of corporate IC and includes information that is pivotal to both investors and other stakeholders (Striukova et al., 2008; Duff, 2018).

In keeping with Striukova et al. (2008) and Duff (2018), in the human capital category, the item "know-how" was replaced by the item "employee/partner"; the items "education" and "vocational qualification" were merged into one item to include comprehensive information on education and vocational qualifications; and, the item "training" was added to take account of the disclosure provided by the company regarding training and formation programmes developed for employees. The items "work-related competencies" and "workrelated knowledge" were replaced by the item "human resource management", which includes all policies relating to employee management and welfare promotion. In the end, three items were added to the human capital category, namely, "recruitment policies" and "career opportunities", which highlight how the company is investing in attracting new human resources and renewing its human capital endowment, and "diversity", which emphasises the gender diversity policies implemented for employees. Ultimately, as shown in Table 1 , a final list of 24 items was obtained.

The second step involved the selection of the unit of analysis. It is at this stage that "researchers need to decide the basis they are going to use to identify whether the item is IC information or not" (Husin et al., 2012, p. 204). Considering the multidimensional nature of websites and the need to exploit their communicative potential, in keeping with scholars (Cinquini, 2012; Terblanche and De Villiers, 2019), a comprehensive unit of analysis was selected, including sentences, graphics, charts and tables. Pictures without surrounding text were excluded, as their inclusion would likely pose challenges in terms of subjective interpretation and impact quantification (Guthrie et al., 2004; Husin et al., 2012). 


\begin{tabular}{|c|c|c|c|}
\hline Internal (structural) capital & External (relational) capital & Human capital & \\
\hline Patents & Brands & Employee & communication \\
\hline Copyrights & Customers & Education and vocational qualifications & \\
\hline Trademarks & Customer satisfaction and loyalty & Training & \\
\hline Corporate culture & Company reputation & Human resource management & determinan \\
\hline Management processes & Distribution channels & Innovativeness of employees/partners & \\
\hline Information systems & Business collaborations & Recruitment policies & \\
\hline Communication systems & Favourable contracts/licensing & Career opportunities & 122 \\
\hline Financial relations & Public relations & Diversity & \\
\hline \multicolumn{3}{|c|}{$\begin{array}{l}\text { Source: Guthrie and Petty (2000), Bozzolan et al. (2003); Guthrie et al. (2006), Striukova et al. (2008); Haji } \\
\text { and Ghazali (2013); Duff (2018) }\end{array}$} & $\begin{array}{l}\text { Table } \\
\text { IC coding framewo }\end{array}$ \\
\hline
\end{tabular}

The third step concerned the coding process. Content analysis was performed manually on the sample of websites, with the information recorded in electronic format (e.g. in Excel) to ensure easy storage, checking, correction and statistical data analysis (Melloni, 2015; Duff, 2018). Manual content analysis was preferred to electronic searching supported by software, as it avoids the possible drawbacks arising from the identification of synonyms and sentences with multiple meanings and simplifies the interpretation and inference of IC information from the surrounding context (Beattie and Thomson, 2007; Duff, 2018). In keeping with previous studies (Striukova et al., 2008; Manes Rossi et al., 2018), only Web pages in Web browser format (e.g. HTML) were considered for analysis, including specific websites features such as hyperlinks, menus and portals from which it was possible to retrieve useful information. Other documents available on websites in PDF or Word form, such annual, sustainability and corporate governance reports; brochures and media releases were omitted from the scope of the study, as they were considered distinct information sources (Striukova et al., 2008; Manes Rossi et al., 2018).

Data collection took place between November and December 2019, a sufficiently short period that allowed any problems arising from Web analysis over a longer period to be circumvented, given that websites are dynamic and subject to frequent changes or maintenance (Duff, 2018; Manes Rossi et al., 2018).

To ensure reliability, after the final coding framework and categories were defined in the first step, a training exercise was performed simultaneously by two coders on a sample of 10 websites. This was a pivotal step aimed at solving any ambiguities, discrepancies and grey areas arising between the coders and also enforcing the coding rules. After the training exercise, the two coders independently assessed a further sample of 15 websites. Krippendorff's $\alpha$ was calculated using an SPSS macro, providing a degree of agreement above the minimum limit of acceptance of 0.8 (Bozzolan et al., 2003; Krippendorff, 2004). After this step, the coders continued independently the analysis on the remaining websites.

Aimed at assessing both the extent and type of online ICD, this study proposes two different disclosure indexes (Guthrie et al., 2006; Haji and Ghazali, 2013; Duff, 2018). The first index (eICD) assesses the extent of ICD and is based on a dichotomous approach. Accordingly, a score of one is given if the IC item was disclosed on the website and a score of zero is assigned otherwise. This approach attributes the same importance to all items and allows potential subjectivity drawbacks to be minimised (Ferreira et al., 2012; Manes Rossi et al., 2018). Moreover, it fosters easy comparisons between similar ICD studies (Striukova et al., 2008).

Therefore, eICD was calculated as follows: 


$$
\text { eICD Index }=\frac{\sum_{\mathbf{i}=1}^{1} \mathbf{d}_{\mathbf{i}}}{\mathbf{l}}
$$

where:

$$
\begin{aligned}
& \mathrm{d}=1 \text { if the item was disclosed and } 0 \text { otherwise; and } \\
& \mathrm{l}=\text { the maximum number of items ( } 24 \text { items). }
\end{aligned}
$$

The second index evaluates the type (form) of ICD (tICD) as, examining only the extent of disclosures could provide biased results in cases where the credibility, type and quality of disclosures play a fundamental role for stakeholders (Beattie and Thomson, 2007). Thus, in line with previous studies (Guthrie et al., 2006; Nurunnabi et al., 2011; Haji and Ghazali, 2013), a coding scale was adopted to assess the type of ICD, which distinguished between three forms of disclosure: narrative (discursive); numerical (quantitative); and monetary (quantified in euro).

More specifically, the tICD was estimated as follows:

$$
\text { tICD Index }=\frac{\sum_{\mathbf{i}=1}^{\mathbf{m}} \mathbf{d}_{\mathbf{i}}}{\mathbf{m}}
$$

where:

dì $=1$ for disclosures in narrative (discursive) terms or;

$\mathrm{di}=2$ for disclosures in numerical (quantitative) terms or;

$\mathrm{di}=3$ for disclosures in monetary (quantified in euro) terms;

$0=$ if the item di is not disclosed; and

$\mathrm{M}=$ maximum possible score $(3 \times 24$ items $=72)$.

\subsection{Empirical models}

Two OLS regression models were estimated to test the hypotheses and assess the extent to which drivers associated with theory and previous research affect the extent and type of online ICD provided by the sample of Italian listed companies.

Both the eICD index and the IICD index were used as dependent variables:

Model (1)

$$
\begin{aligned}
\mathrm{eICD}= & \beta_{0}+\beta_{1}(\text { Size })+\beta_{2}(\text { Profitability })+\beta_{3}(\text { Leverage })+\beta_{4}(\text { Industry }) \\
& +\beta_{5}(\text { Board Size })+\beta_{6}(\text { Board Independence })+\varepsilon \mathrm{i}
\end{aligned}
$$

Model (2)

$$
\begin{aligned}
\operatorname{tICD}= & \beta_{0}+\beta_{1}(\text { Size })+\beta_{2}(\text { Profitability })+\beta_{3}(\text { Leverage })+\beta_{4}(\text { Industry }) \\
& +\beta_{5}(\text { Board Size })+\beta_{6}(\text { Board Independence })+\varepsilon \mathrm{i}
\end{aligned}
$$

The independent variables were operationalised as follows:

Size was proxied by the natural logarithm of total assets (Nurunnabi et al., 2011; Goebel, 2019); profitability was calculated as the return on assets computed as the net profit divided by the total assets (Oliveira et al., 2006; Ferreira et al., 2012); leverage was proxied by the ratio of total debts to total assets (Hidalgo et al., 2011; Abdul Rashid et al., 2012); industry was proxied by a binary variable equal to (1) if the company belonged to a high-tech 
industry sector and to (0) otherwise (Oliveira et al., 2006; Bruggen et al., 2009; Goebel, 2019); board size was calculated as the number of board members in the company, while board independence was calculated as the proportion of independent directors on the board ( $\mathrm{Li}$ et al., 2008; Haji and Ghazali, 2013).

\section{Content analysis results: extent and quality of ICD}

Table 2 shows the content analysis results by item and disclosure type.

On average, each sampled company was found to disclose about $73 \%$ of the total IC items online. This result is higher than the results of previous studies conducted on annual reports

(Guthrie et al., 2006; Nurunnabi et al., 2011; Ferreira et al., 2012; Haji and Ghazali, 2013), but

\begin{tabular}{|c|c|c|c|c|c|c|}
\hline & & & & pe of IC disclosu & & \\
\hline & ems & N. of firms & $\begin{array}{l}\text { Narrative } \\
\text { (discursive) }\end{array}$ & $\begin{array}{c}\text { Numerical } \\
\text { (quantitative) }\end{array}$ & $\begin{array}{l}\text { Monetary } \\
(€)\end{array}$ & \\
\hline & rnal (structural) capital & & & & & \\
\hline 1 & Patents & 22 & 12 & 10 & 0 & \\
\hline 2 & Copyrights & 5 & 5 & 0 & 0 & \\
\hline 3 & Trademarks & 89 & 80 & 9 & 0 & \\
\hline 4 & Corporate culture & 109 & 108 & 1 & 0 & \\
\hline 5 & Management processes & 101 & 99 & 2 & 0 & \\
\hline 6 & Information systems & 117 & 14 & 5 & 98 & \\
\hline 7 & Communication systems & 116 & 116 & 0 & 0 & \\
\hline 8 & Financial relations & 115 & 10 & 103 & 2 & \\
\hline & al internal (structural capital) & 674 & 444 & 130 & 100 & \\
\hline & al internal (structural capital) (\%) & 72 & 66 & 19 & 15 & \\
\hline & ernal (relational) capital & & & & & \\
\hline 1 & Brands & 90 & 78 & 12 & 0 & \\
\hline 2 & Customers & 109 & 78 & 31 & 0 & \\
\hline 3 & Customer satisfaction and loyalty & 99 & 85 & 9 & 5 & \\
\hline 4 & Company reputation & 98 & 95 & 3 & 0 & \\
\hline 5 & Distribution channels & 112 & 47 & 63 & 2 & \\
\hline 6 & Business collaborations & 111 & 75 & 34 & 2 & \\
\hline 7 & Favourable contracts/licensing & 100 & 85 & 14 & 1 & \\
\hline 8 & Public relations & 69 & 48 & 11 & 10 & \\
\hline & al external (relational) capital & 788 & 591 & 177 & 20 & \\
\hline & al external (relational) capital (\%) & 84 & 75 & 22 & 3 & \\
\hline & nan capital & & & & & \\
\hline 1 & Employee & 102 & 35 & 67 & 0 & \\
\hline 2 & Education and vocational qualifications & 77 & 69 & 8 & 0 & \\
\hline 3 & Training & 67 & 47 & 17 & 3 & \\
\hline 4 & Human resource management & 61 & 60 & 1 & 0 & \\
\hline 5 & Innovativeness of employees/partners & 85 & 85 & 0 & 0 & \\
\hline 6 & Recruitment policies & 67 & 65 & 2 & 0 & \\
\hline 7 & Career opportunities & 89 & 89 & 0 & 0 & \\
\hline & Diversity & 51 & 27 & 24 & 0 & \\
\hline & al human capital & 599 & 477 & 119 & 3 & Table 2. \\
\hline & al human capital (\%) & 64 & 79 & 20 & 1 & Content analysis \\
\hline & al ICD & 2061 & 1512 & 426 & 123 & results. Extent and \\
\hline & al ICD (\%) & 73 & 73 & 21 & 6 & type of IC disclosure \\
\hline
\end{tabular}

ICD corporate communication and its determinants

1223 
MEDAR 29,5

\section{4}

it is in line with more recent studies focussed on websites, although conducted in the university context (Manes Rossi et al., 2018; Ndou et al., 2018). In particular, this result gives echo to Dumay and Guthrie (2017, pp. 32-33) who advocated that:

Now stakeholders rely on so much more information and communication, from a much wider variety of sources that is timelier and more relevant than that found in the accounting and annual reports of today.

Accordingly, the above finding highlights that ICD patterns are evolving towards more interactive, dynamic and timely communication tools that will allow companies to overcome the limitations of traditional financial reports and better satisfy the growing information needs of investors and other stakeholders regarding organisations' IC-based strategic resources and their contribution to the value creation process (Lardo et al., 2017; La Torre et al., 2018). From the standpoint of the fourth stage of IC research, this result evidences how the new information technologies are progressively breaking down the boundaries between the company and the external ecosystem, allowing companies to convey more information on IC than using other tools and to target a wider audience in an accessible and timely manner (La Torre et al., 2018; Ndou et al., 2018).

In line with previous studies (Bozzolan et al., 2003; Guthrie et al., 2006; Melloni, 2015; Haji and Anifowose, 2017; Goebel, 2019), a prevalence towards relational capital category emerges ( Figure 1). In particular, wide attention is devoted to the disclosure of information on brands, customers (satisfaction and loyalty), distribution channels, reputation and favourable contracts/licensing, all of which were reported online by more than $75 \%$ of the sample.

This result confirms how in an evolving economic context, the company's survival strictly depends on its ability to successfully manage its relationships with powerful stakeholders such as customers and suppliers (Guthrie et al., 2006; Bruggen et al., 2009) and also to develop common paths of value creation and knowledge sharing through synergies, collaborations and the implementation of adequate customer loyalty and retention programmes. Accordingly, Italian listed companies are using websites to convey information on relational capital, to improve dialogue with external stakeholders and shift the focus of IC from the company as a single entity to a broader ecosystem in which knowledge is generated, developed and shared on a wider spectrum (Dumay and Garanina, 2013; Massaro et al., 2018.

Figure 1. ICD extent distribution per categories

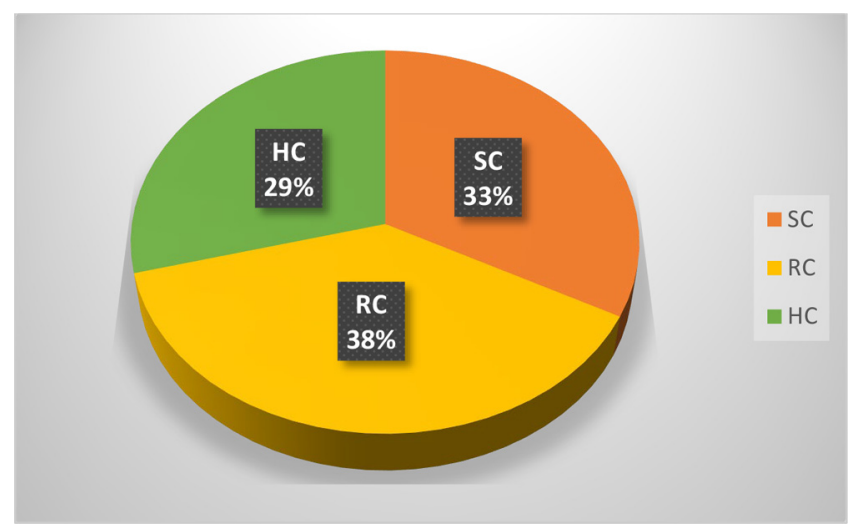


However, although a fair level of disclosure was also observed for internal and human capital, as found in previous studies (Bozzolan et al., 2003; Garcia-Meca and Martinez, 2005; Striukova et al., 2008), there is still reluctance to disclose information on some items (e.g. patents; copyrights; human resource management), as the perceived risk attached to providing commercially sensitive information that can be exploited by competitors outweighs the need to satisfy investors' and other stakeholders' information needs (Oliveira et al., 2006).

In line with previous studies (Guthrie et al., 2006; Striukova et al., 2008; Nurunnabi et al., 2011; Haji and Ghazali, 2013), Table 2 also confirms the predominance of narrative

ICD corporate communication and its determinants

1225 (discursive) ICD, which accounts for approximately $73 \%$ of ICD. In contrast, only $21 \%$ of ICD is conveyed in numerical (quantitative) form and 6\%, in monetary form. Although narrative disclosure is pivotal in explaining "the reasons underlying an organisation's management of IC" (Dumay and Roslender, 2013, p. 249) and provides stakeholders with a more comprehensive picture of companies' value creation processes, quantitative disclosure is deemed to be of higher quality, as it is measurable and verifiable (Terblanche and De Villiers, 2019). Therefore, the prevalence of narrative disclosures sheds light on the difficulties managers face in trying to quantify and estimate the economic impact of IC resources and also highlights the problems associated with preventing competitive damages potentially arising from the disclosure of excessively specific and accurate information on strategic resources such as IC (Guthrie and Petty, 2000; Guthrie et al., 2006) via largely accessible communication tools such as websites.

\section{Hypothesis testing results}

\subsection{Descriptive statistics and correlation analysis}

Table 3 shows the results of the descriptive statistics for the independent variables, outlining the minimum, maximum and mean values, as well as the standard deviation.

Table 4 presents the Pearson correlation matrix for the dependent and independent variables. The value of the correlation between ICD and IICD is omitted as they were tested in different regression models. In general, all of the correlation values are well below the critical threshold of 0.8 , indicating no severe multicollinearity problems (Nurunnabi et al., 2011; Abdul Rashid et al., 2012). A positive and significant association $(\phi<0.01)$ was detected between eICD and both size and board independence. A positive and significant correlation was also observed between tICD and size $(\phi<0.01)$, board size $(p<0.05)$ and board independence $(p<0.01)$. Finally, while a negative correlation between profitability and leverage was found $(p<0.01)$, a positive correlation was observed between size and both board size and board independence $(p<0.01)$.

\begin{tabular}{lcccr}
\hline Continuous variables & Min & Max & Mean & SD \\
\hline Size & 8.806 & 17.929 & 13.0676 & 1.6808 \\
Profitability & -28.39 & 28.55 & 2.1088 & 7.2849 \\
Leverage & 0.0207 & 1.1591 & 0.5161 & 0.2250 \\
Board size & 5.0 & 17.0 & 9.684 & 2.6544 \\
Board independence & 0.2 & 0.87 & 0.47 & 0.1407 \\
Dummy variables & $\mathrm{Y} / \mathrm{N}$ & & & \\
Industry (high-tech) & $17 / 100$ & & & \\
& $14.5 \% / 85.5 \%$ & & & \\
\end{tabular}

Table 3.

Descriptive statistics for independent variables 


\section{MEDAR 29,5}

\begin{tabular}{llccccccc}
\hline & 1 & 2 & 3 & 4 & 5 & 6 & 7 & \multicolumn{1}{c}{8} \\
\hline 1. ICD extent & 1 & $0.892^{* * *}$ & $0.452^{* *}$ & 0.105 & 0.152 & -0.008 & 0.175 & $0.342^{* *}$ \\
2. ICD quality & & 1 & $0.523^{* *}$ & 0.102 & 0.141 & -0.051 & $0.228^{*}$ & $0.367^{* *}$ \\
3. Size & & & 1 & 0.076 & 0.119 & -0.146 & $0.501^{* *}$ & $0.462^{* *}$ \\
4. Profitability & & & & 1 & $-0.277^{* *}$ & -0.152 & 0.054 & 0.036 \\
5. Leverage & & & & 1 & -0.040 & -0.127 & 0.053 \\
6. Industry (high-tech) & & & & & 1 & -0.042 & -0.008 \\
7. Board size & & & & & & & 1 & 0.073 \\
8. Board independence & & & & & & & & 1
\end{tabular}

Table 4.

8. Board independence

Correlation analysis Notes: $* p<0.05 ; * * p<0.01$ (two-tailed)

\subsection{Multivariate regression models}

Two OLS regression models were estimated to test the six hypotheses by considering two dependent variables - the eICD index and the tICD index. All independent variables were included in both models.

As shown in Tables 5 and 6, the assumptions underlying the regression models were tested for multicollinearity [variance influence factor (VIF) and tolerance levels calculation]; heteroscedasticity (Breusch-Pagan and White tests); and both errors and residual normality issues (OLS model normality test and Jarque-Bera test). All the VIFs were lower than the critical threshold of 10 and all of the values for tolerance levels were significantly higher than 0.10, thus indicating no multicollinearity drawbacks. Both White's and BreuschPagan's heteroscedasticity tests provided $p$-values that were not significant, thus eliminating heteroscedasticity problems. Moreover, the results of the test for the normality of residuals and the results of the Jarque-Bera test evidenced that the residuals showed normal behaviour and that the errors were distributed normally.

\begin{tabular}{lccccccc}
\hline & Coefficient & Std error & T-statistic & $p$-value & Sig. & Tol. & VIF \\
\hline Const & 0.153607 & 0.0806834 & 1.904 & 0.0595 & $*$ & & \\
Size & 0.0334925 & 0.00978638 & 3.422 & 0.0009 & $* * *$ & 0.525 & 1.906 \\
Profitability & 0.00253859 & 0.00138071 & 1.839 & 0.0687 & $*$ & 0.887 & 1.127 \\
Leverage & 0.0928101 & 0.0677585 & 1.370 & 0.1736 & & 0.854 & 1.170 \\
Industry (high-tech) & 0.0305990 & 0.0305667 & 1.001 & 0.3190 & & 0.948 & 1.054 \\
Board size & -0.000337604 & 0.00655246 & -0.05152 & 0.9590 & & 0.679 & 1.474 \\
Board independence & 0.180185 & 0.0892139 & 2.020 & 0.0458 & $* *$ & 0.747 & 1.339 \\
Model specification: & & & & & & & \\
Mean dep. variabile & & 0.730769 & Std dev. dep. variable & & 0.154701 \\
Sum of squared residuals & & 2.076569 & Regression std error & & & 0.137397 \\
$R^{2}$ & 0.252004 & Adjusted $R^{2}$ & & & 0.211204 \\
F(6.110) & 12.72519 & p-value(F) & & & 0.000000
\end{tabular}

Table 5.

OLS regression model results and tests - Model (1) eICD index
Normality OLS model test: T Statistic: $\chi^{2}(2)=3.22913 ; p$-value $=0.198977$ (errors are normally distributed) Jarque-Bera test: T statistic: $2.49972 ; p$-value $=0.286545$ (residuals are normally distributed)

Breusch-Pagan test: T statistic: $\mathrm{LM}=6.06677 ; p$-value $=p\left(\chi^{2}(6)>6.0677\right)=0.415752$ (not heteroskedasticity) White test: T statistic: $\mathrm{LM}=30.6008 ; p$-value $=p\left(\chi^{2}(26)>30.6008\right)=0.243471$ (not heteroskedasticity)

Notes: The asterisks indicate statistical significance at the following levels: *10\%; **5\%; ***1\% 


\begin{tabular}{|c|c|c|c|c|c|c|c|}
\hline & Coefficient & Std error & $T$-statistic & $p$-value & Sig. & Tol. & VIF \\
\hline Const & -0.0139830 & 0.0431723 & -0.3239 & 0.7466 & & & \\
\hline Size & 0.0204949 & 0.00519433 & 3.946 & 0.0001 & $* * *$ & 0.525 & 1.906 \\
\hline Profitability & 0.00110372 & 0.000702396 & 1.571 & 0.1190 & & 0.887 & 1.127 \\
\hline Leverage & 0.0403368 & 0.0349801 & 1.153 & 0.2514 & & 0.854 & 1.170 \\
\hline Industry (high-tech) & 0.00747182 & 0.0173757 & 0.4300 & 0.6680 & & 0.948 & 1.054 \\
\hline Board size & 0.000395305 & 0.00341885 & 0.1156 & 0.9082 & & 0.679 & 1.474 \\
\hline Board independence & 0.0918572 & 0.0465486 & 1.973 & 0.0510 & * & 0.747 & 1.339 \\
\hline \multicolumn{8}{|l|}{ Model specification: } \\
\hline \multicolumn{2}{|l|}{ Mean dep. variabile } & 0.325261 & \multicolumn{3}{|c|}{ Std dev. dep. variable } & \multicolumn{2}{|r|}{0.080847} \\
\hline \multirow{2}{*}{\multicolumn{2}{|c|}{$\begin{array}{l}\text { Sum of squared residuals } \\
R^{2}\end{array}$}} & 0.524155 & \multirow{2}{*}{\multicolumn{3}{|c|}{$\begin{array}{l}\text { Regression std error } \\
\text { Adjusted } R^{2}\end{array}$}} & \multirow{2}{*}{\multicolumn{2}{|c|}{$\begin{array}{l}0.069029 \\
0.270971\end{array}$}} \\
\hline & & 0.308680 & & & & & \\
\hline \multicolumn{2}{|l|}{$\mathrm{F}(6.110)$} & 13.92878 & \multicolumn{2}{|c|}{$p$-value $(\mathrm{F})$} & & \multicolumn{2}{|r|}{0.000000} \\
\hline
\end{tabular}

Normality OLS model test: T Statistic: $\chi^{2}(2)=0.561272 ; p$-value $=0.755303$ (errors are normally distributed) Jarque-Bera test: $T$ statistic: $0.910152 ; p$-value $=0.6344$ (residuals are normally distributed)

Breusch-Pagan test: T statistic: $\mathrm{LM}=2.42057 ; p$-value $=p\left(\chi^{2}(6)>2.42057\right)=0.877249$ (not heteroskedasticity) White test: T statistic: $\mathrm{LM}=27.3834 ; p$-value $=p\left(\chi^{2}(26)>27.3834\right)=0.389447$ (not heteroskedasticity)

Notes: The asterisks indicate statistical significance at the following levels: * $10 \%$; $* * 5 \%$; ***1\%

ICD corporate communication and its determinants

1227

Both of the OLS regression models were statistically significant at the $1 \%$ level $(\phi$-value $<0.01)$ and showed fair explanatory power; adjusted $R^{2}$ is 0.21 for the model (1) and 0.27 for the model (2).

In both models, two variables out of six are positive and statistically significant: size and board independence. Profitability is positive and statistically significant only in the first model. Conversely, leverage, high-tech industry involvement and board size did not show any significant effect on both extent and type of ICD.

The positive and significant relationship detected between size and extent and type of ICD confirms the first hypothesis and the results obtained in previous studies on annual reports (Bozzolan et al., 2003; Guthrie et al., 2006; Nurunnabi et al., 2011; Haji and Ghazali, 2013). However, different from prior research on ICD conducted on traditional financial reports, this result assumes pivotal relevance as websites allow firms to reach a wider audience than such reports, enhancing firms' visibility and the degree of scrutiny of stakeholders (Kelton and Yang, 2008; Cormier et al., 2009). Accordingly, in line with the stakeholder theory, our results demonstrate that larger Italian listed companies tend to provide a higher and more qualitative level of ICD through their websites to satisfy the information needs of a wider range of stakeholders requiring information about critical success factors based on IC resources and their contribution to the value creation processes (Guthrie et al., 2006; Oliveira et al., 2006).

This result also provides an argument in support of the notion that larger companies have more economic, financial and organisational resources to devote to the adoption and development of new information technologies based on internet usage, which enables them to convey more IC information and therefore enhance their dialogue with investors and other stakeholders (Oliveira et al., 2006; Boubaker et al., 2011; Ferreira et al., 2012; Lee and Blouin, 2019). Larger companies may also rely on more skilled and capable managers who are able to provide higher-quality IC information based on quantitative and monetary assessments of IC resources (Oliveira et al., 2006; Boubaker et al., 2011; Lee and Blouin, 2019). 
MEDAR 29,5

The positive and significant association between board independence and both the extent and type of online ICD is in line with expectations and with previous studies conducted on traditional annual reports (Cerbioni and Parbonetti, 2007; Li et al., 2008; Haji and Ghazali, 2013). This allows confirming the pivotal role played by corporate governance mechanisms in determining voluntary disclosure policies also in the website domain (Kelton and Yang, 2008). More specifically, this result provides arguments supporting the relevance of independent board members in curbing managers' opportunistic behaviours and ensuring the alignment of interests between managers, shareholders and stakeholders, through a specific monitoring function that stimulates a greater level of online ICD and quality (Jensen and Meckling, 1976; Li et al., 2008; Hidalgo et al., 2011).

This assumes particular importance in the Italian context, where the massive presence of large controlling shareholders may negatively influence the efficiency and effectiveness of boards (Allegrini and Greco, 2013). Accordingly, in line with the stakeholder theory, our results demonstrate that a greater presence of independent members, typically sensitive to social demands and interested in preserving their reputation as external referees, will encourage more corporate transparency on IC to the benefits of the whole of stakeholders (Abdul Rashid et al., 2012; Allegrini and Greco, 2013; Haji and Ghazali, 2013).

Finally, in keeping with previous studies (Cerbioni and Parbonetti, 2007; Li et al., 2008; Haji and Ghazali, 2013), profitability positively affects the extent of ICD provided by Italian listed companies via the Web. From a stakeholder theory standpoint, this result highlights that more profitable Italian listed companies provide a higher level of ICD through websites, to justify their profits to stakeholders as the outcome of long-term investment in the creation and development of IC resources (Oliveira et al., 2006; Ferreira et al., 2012). This positive association also confirms that more profitable companies have more financial resources to invest in the development of new communication technologies and IT capabilities (Boubaker et al., 2011; Lee and Blouin, 2019), which, in turn, results in a higher level of web-based ICD.

\section{Conclusion}

In recent years, in the light of the fourth industrial revolution, the new wave of digital technologies has been hailed by researchers as an opportunity to collect, manage and share IC information and support investors and other stakeholders in better understanding and evaluating companies' intangible resources (Al-Htaybat and von Alberti-Alhtaybat, 2017; Lombardi and Dumay, 2017; La Torre et al., 2018).

Therefore, scholars advocate that investigating online communication tools is pivotal to gathering relevant insights that will be enhancing the understanding of the level of IC information disclosed by modern organisations beyond the traditional static and backwards-looking financial reports which, for many years, represented the main focus of ICD studies (Lombardi and Dumay, 2017; Massaro et al., 2017; Ndou et al., 2018).

On that basis, the present study contributes to the literature, providing fresh insight into the extent and type of online ICD communicated by a sample of 117 Italian listed companies.

The research is also significant as it broadens the boundaries of previous similar research (Striukova et al., 2008; Sharma and Kaur, 2016; Duff, 2018), providing insights about the factors that could explain practices of IC voluntary disclosure made by listed companies through websites. In doing so, it extends the analysis of the most commonly examined variables in previous ICD studies, which largely focussed on annual reports, to the website domain.

The paper provides empirical evidence supporting the argument that ICD patterns are moving towards more interactive, dynamic and timely communication tools such as websites, which allow companies to better satisfy the growing information needs of investors and other stakeholders in relation to IC (Lardo et al., 2017; La Torre et al., 2018). In 
light of the fourth stage of IC research, our results highlight how Italian listed companies are exploiting the internet to provide a large quantity of ICD, with a particular focus on external capital, to blur the boundaries with the external ecosystem and address the expectations of a wider audience of stakeholders (La Torre et al., 2018; Ndou et al., 2018). Moreover, the analysis of possible explanatory factors underlines that larger Italian listed companies because they deal with a wider forum of stakeholders and are subject to greater political and social pressures, tend to provide a greater level of ICD to meet the expectations placed on them. As expected, a pivotal role is played by independent board members who, against a

ICD corporate communication and its determinants

1229 backdrop in which large controlling shareholders dominate, act as a deterrent for opportunistic behaviours and safeguard the interests of outsiders (e.g. less informed minority shareholders, outside shareholders or external stakeholders) by encouraging a greater level of ICD. Finally, the results confirm that more profitable companies have a greater level of financial resources to invest in new communication technologies (Boubaker et al., 2011; Lee and Blouin, 2019), which ultimately leads to a higher level of Web-based ICD to stakeholders.

This study also has implications for academics and practitioners. Academics may replicate the study by using or adapting the same coding framework to examine the level of online ICD provided by firms from other international regions, possibly extending the use of variables to other possible explanatory factors that may include other corporate governance attributes (e.g. gender diversity on the board, board meetings, the educational background of board members).

Standard setters and regulators may consider these results with a view to evaluating the introduction of adequate guidelines to promote ICD, including utilisation of online media tools and also with a view to gaining a better understanding of the factors that drive the voluntary disclosure of IC information by companies. They may also draw on this knowledge in discussions on the formulation of future accounting standards in relation to intangible assets. The study also provides practical insights that could be leveraged to underpin Italian policies regarding the relevance of independent directors, with the aim of limiting the possibilities for large controlling shareholders to maximise private benefits. Results may also be beneficial for board members to evaluating the role of certain governance mechanisms in stimulating a higher level of ICD, as well as for firms' managers to gain further awareness about the pivotal role that online tools play in reducing information asymmetries with uninformed investors and other stakeholders.

However, the findings of the study must be interpreted in the context of the following limitations, which pave the way for new research opportunities. Firstly, the research only incorporates a single year, thus failing to examine reporting trends over time. A further possible direction for this research may be contemplation of a longitudinal analysis of online ICD over multiple years. Secondly, the research is focused on a single geographical context, namely, Italy. Future studies could conduct cross-national comparisons to assess the extent to which online ICD is country-specific or a European/worldwide phenomenon. Thirdly, the study is focussed on a limited number of variables due to lack of further data and to preserve the consistency of the statistical analyses. To address this limitation, future studies may investigate further variables relating to other corporate governance mechanisms or corporate performance variables. Fourthly, in the wake of the emergence of modern digital technologies and format, future studies may also investigate social media such as Facebook and Twitter or other tools providing BD to examine further, innovative avenues for voluntary ICD practices. Furthermore, it could be interesting to develop a specific disclosure index covering indicators of the average level of firms' digitalisation, based on the IC resources. 
MEDAR 29,5

\section{References}

Abdul Rashid, A., Ibrahim, M.K., Othman, R. and See, K.F. (2012), "IC disclosures in IPO prospectuses: evidence from Malaysia”, Journal of Intellectual Capital, Vol. 13 No. 1, pp. 57-80.

Al-Htaybat, K. and von Alberti-Alhtaybat, L. (2017), "Big data and corporate reporting: impacts and paradoxes", Accounting, Auditing and Accountability Journal, Vol. 30 No. 4, pp. 850-873.

Allegrini, M. and Greco, G. (2013), "Corporate boards, audit committees and voluntary disclosure: evidence from Italian listed companies", Journal of Management and Governance, Vol. 17 No. 1, pp. 187-216.

Beattie, V. and Thomson, S.J. (2007), "Lifting the lid on the use of content analysis to investigate intellectual capital disclosures", Accounting Forum, Vol. 31 No. 2, pp. 129-163.

Boubaker, S., Lakhal, F. and Nekhili, M. (2011), “The determinants of web-based corporate reporting in France", Managerial Auditing Journal, Vol. 27 No. 2, pp. 126-155.

Bozzolan, S., Favotto, F. and Ricceri, F. (2003), "Italian annual intellectual capital disclosure: an empirical analysis", Journal of Intellectual Capital, Vol. 4 No. 4, pp. 543-558.

Bruggen, A., Vergauwen, P. and Dao, M. (2009), "Determinants of intellectual capital disclosure: evidence from Australia”, Management Decision, Vol. 47 No. 2, pp. 233-245.

Bukh, P.N., Nielsen, C., Gormsen, P. and Mouritsen, J. (2005), "Disclosure of information on intellectual capital in Danish IPO prospectuses", Accounting, Auditing and Accountability Journal, Vol. 18 No. 6, pp. 713-732.

Cerbioni, F. and Parbonetti, A. (2007), "Exploring the effects of corporate governance on intellectual capital disclosure: an analysis of European biotechnology companies", European Accounting Review, Vol. 16 No. 4, pp. 791-826.

Cinquini, L. (2012), "Analyzing intellectual capital information in sustainability reports: some empirical evidence", Journal of Intellectual Capital, Vol. 13 No. 4, pp. 531-561.

Cormier, D., Ledoux, M.J. and Magnan, M. (2009), "The use of web sites as a disclosure platform for corporate performance", International Journal of Accounting Information Systems, Vol. 10 No. 1, pp. 1-24.

Cuozzo, B., Dumay, J., Palmaccio, M. and Lombardi, R. (2017), "Intellectual capital disclosure: a structured literature review", Journal of Intellectual Capital, Vol. 18 No. 1, pp. 9-28.

Deegan, C. (2000), "Firms' disclosure reactions to major social incidents: Australian evidence", Accounting Forum, Vol. 24 No. 1, pp. 101-130.

Duff, A. (2018), "Intellectual capital disclosure: evidence from UK accounting firms", Journal of Intellectual Capital, Vol. 19 No. 4, pp. 768-786.

Dumay, J. (2016), “A critical reflection on the future of intellectual capital: from reporting to disclosure", Journal of Intellectual Capital, Vol. 17 No. 1, pp. 168-184.

Dumay, J. and Garanina, T. (2013), "Intellectual capital research: a critical examination of the third stage", Journal of Intellectual Capital, Vol. 14 No. 1, pp. 10-25.

Dumay, J. and Roslender, R. (2013), "Utilising narrative to improve the relevance of intellectual capital", Journal of Accounting and Organizational Change, Vol. 9 No. 3, pp. 248-279.

Dumay, J. and Guthrie, J. (2017), "Involuntary disclosure of intellectual capital: is it relevant?", Journal of Intellectual Capital, Vol. 18 No. 1, pp. 30-45.

Edvinsson, L. and Malone, M. (1997), Intellectual Capital: Realising Your Company's True Value by Finding Its Hidden Brainpower, Harper Business (A division of Harper Collins Publishers), New York, NY.

Ferreira, A.L., Branco, M.C. and Moreira, J.A. (2012), "Factors influencing intellectual capital disclosure by Portuguese companies", International Journal of Accounting and Financial Reporting, Vol. 2 No. 2, p. 278.

Forte, W., Matonti, G., Nicolò, G. and Tucker, J. (2019), "MtB versus VAIC in measuring intellectual capital: empirical evidence from Italian listed companies", African Journal of Business Management, Vol. 13 No. 17, pp. 588-601. 
Gajewski, J.F. and Li, L. (2015), “Can internet-based disclosure reduce information asymmetry?”, Advances in Accounting, Vol. 31 No. 1, pp. 115-124.

Garcia-Meca, E. and Martinez, I. (2005), "Assessing the quality of disclosure on intangibles in the spanish capital market”, European Business Review, Vol. 17 No. 4, pp. 305-313.

Goebel, V. (2019), "Drivers for voluntary intellectual capital reporting based on agency theory", Journal of Intellectual Capital, Vol. 20 No. 2, pp. 264-281.

Gray, R., Kouhy, R. and Lavers, S. (1995), "Corporate social and environmental reporting: a review of the literature and a longitudinal study of UK disclosure", Accounting, Auditing and Accountability Journal, Vol. 8 No. 2, pp. 47-77.

Guthrie, J. and Petty, R. (2000), "Intellectual capital: Australian annual reporting practices", Journal of Intellectual Capital, Vol. 1 No. 3, pp. 241-251.

Guthrie, J., Petty, R. and Ricceri, F. (2006), "The voluntary reporting of intellectual capital: comparing evidence from Hong Kong and Australia”, Journal of Intellectual Capital, Vol. 7 No. 2, pp. 254-271.

Guthrie, J., Petty, R. and Yongvanich, K. (2004), "Using content analysis as a research method to inquire into intellectual capital reporting”, Journal of Intellectual Capital, Vol. 5 No. 2, pp. 282-293.

Haji, A.A. and Ghazali, M.N. (2013), "A longitudinal examination of intellectual capital disclosures and corporate governance attributes in Malaysia", Asian Review of Accounting, Vol. 21 No. 1, pp. $27-52$.

Haji, A.A. and Anifowose, M. (2017), "Initial trends in corporate disclosures following the introduction of integrated reporting practice in South Africa”, Journal of Intellectual Capital, Vol. 18 No. 2, pp. 373-399.

Hidalgo, R.L., García-Meca, E. and Martínez, I. (2011), "Corporate governance and intellectual capital disclosure", Journal of Business Ethics, Vol. 100 No. 3, pp. 483-495.

Husin, N.M., Hooper, K. and Olesen, K. (2012), "Analysis of intellectual capital disclosure - an illustrative example", Journal of Intellectual Capital, Vol. 13 No. 2, pp. 196-220.

Jensen, M.C. and Meckling, W.H. (1976), "Theory of firm: managerial behaviour, agency costs and ownership structure", Journal of Financial Economics, Vol. 3 No. 4, pp. 305-360.

Kelton, A.S. and Yang, Y.W. (2008), "The impact of corporate governance on internet financial reporting", Journal of Accounting and Public Policy, Vol. 27 No. 1, pp. 62-87.

Krippendorff, K. (2004), Content Analysis: An Introduction to Its Methodology, 2nd ed., Sage Publications, Thousand Oaks, CA.

La Torre, M., Botes, V.L., Dumay, J., Rea, M.A. and Odendaal, E. (2018), "The fall and rise of intellectual capital accounting: new prospects from the big data revolution", Meditari Accountancy Research, Vol. 26 No. 3, pp. 381-399.

Lardo, A., Dumay, J., Trequattrini, R. and Russo, G. (2017), "Social media networks as drivers for intellectual capital disclosure: evidence from professional football clubs", Journal of Intellectual Capital, Vol. 18 No. 1, pp. 63-80.

Lee, R.L. and Blouin, M.C. (2019), "Factors affecting web disclosure adoption in the nonprofit sector", Journal of Computer Information Systems, Vol. 59 No. 4, pp. 363-372.

Li, J., Pike, R. and Haniffa, R. (2008), "Intellectual capital disclosure and corporate governance structure in UK firms", Accounting and Business Research, Vol. 38 No. 2, pp. 137-159.

Lombardi, R. and Dumay, J. (2017), "Exploring corporate disclosure and reporting of intellectual capital: revealing emerging innovations", Journal of Intellectual Capital, Vol. 18 No. 1, pp. 2-8.

Manes Rossi, F., Nicolò, G. and Tartaglia Polcini, P. (2018), "New trends in intellectual capital reporting: exploring online intellectual capital disclosure in Italian universities", Journal of Intellectual Capital, Vol. 19 No. 4, pp. 814-835.

Massaro, M., Dumay, J. and Bagnoli, C. (2017), "When the investors speak: intellectual capital disclosure and the Web 2.0", Management Decision, Vol. 55 No. 9, pp. 1888-1904. 
MEDAR 29,5

Massaro, M., Dumay, J., Garlatti, A. and Dal Mas, F. (2018), "Practitioners' views on intellectual capital and sustainability: from a performance-based to a worth-based perspective", Journal of Intellectual Capital, Vol. 19 No. 2, pp. 367-386.

Melloni, G. (2015), "Intellectual capital disclosure in integrated reporting: an impression management analysis", Journal of Intellectual Capital, Vol. 16 No. 3, pp. 661-680.

Ndou, V., Secundo, G., Dumay, J. and Gjevori, E. (2018), "Understanding intellectual capital disclosure in online media big data: an exploratory case study in a university", Meditari Accountancy Research, Vol. 26 No. 3, pp. 499-530.

Nicolò, G. (2020), The Rise of Intellectual Capital Disclosure from Private to Public Sector: The Case of Italian Public Universities, Collana Accounting and Business Studies, FrancoAngeli.

Ntim, C.G., Soobaroyen, T. and Broad, M.J. (2017), "Governance structures, voluntary disclosures and public accountability: the case of UK higher education institutions", Accounting, Auditing and Accountability Journal, Vol. 30 No. 1, pp. 65-118.

Nurunnabi, M., Hossain, M. and Hossain, (2011), "Intellectual capital reporting in a South Asian country: evidence from Bangladesh", Journal of Human Resource Costing and Accounting, Vol. 15 No. 3, pp. 196-233.

Oliveira, L., Rodrigues, L.L. and Craig, R. (2006), "Firm-specific determinants of intangibles reporting: evidence from the Portuguese stock market", Journal of Human Resource Costing and Accounting, Vol. 10 No. 1, pp. 11-33.

Palazzi, F., Sgrò, F., Ciambotti, M. and Bontis, N. (2020), "Technological intensity as a moderating variable for the intellectual capital - performance relationship", Knowledge and Process Management, Vol. 27 No. 1, pp. 3-14.

Prado-Lorenzo, J.M. and Garcia-Sanchez, I.M. (2010), "The role of the board of directors in disseminating relevant information on greenhouse gases", Journal of Business Ethics, Vol. 97 No. 3, pp. 391-424.

Secundo, G., Del Vecchio, P., Dumay, J. and Passiante, G. (2017), "Intellectual capital in the age of big data: establishing a research agenda", Journal of Intellectual Capital, Vol. 18 No. 2, pp. 242-261.

Sharma, K. and Kaur, M. (2016), "Web based disclosure practices of intangible assets of selected Indian companies-an empirical study", Imperial Journal of Interdisciplinary Research, Vol. 2 No. 3, pp. 521-528.

Sonnier, B.M. (2008), "Intellectual capital disclosure: high-tech versus traditional sector companies", Journal of Intellectual Capital, Vol. 9 No. 4, pp. 705-722.

Striukova, L., Unerman, J. and Guthrie, J. (2008), "Corporate reporting of intellectual capital: evidence from UK companies”, The British Accounting Review, Vol. 40 No. 4, pp. 297-313.

Sveiby, K.E. (1997), The New Organizational Wealth: Managing and Measuring Knowledge Based Assets, Berrett-Koehler, San Francisco, CA.

Terblanche, W. and de Villiers, C. (2019), "The influence of integrated reporting and internationalisation on intellectual capital disclosures", Journal of Intellectual Capital, Vol. 20 No. 1, pp. 40-59.

\section{Further reading}

Massaro, M., Dumay, J. and Bagnoli, C. (2017), "When the investors speak: intellectual capital disclosure and the web 2.0", Management Decision, Vol. 55 No. 9, pp. 1888-1904.

\section{Corresponding author}

Giuseppe Nicolò can be contacted at: gnicolo@unisa.it

For instructions on how to order reprints of this article, please visit our website:

www.emeraldgrouppublishing.com/licensing/reprints.htm

Or contact us for further details: permissions@emeraldinsight.com 